\title{
ANALYSIS OF PRESSURE REDUCING EFFECTIVENESS IN THE REFORMING INDUSTRIAL UNIT WITH MATHEMATICAL MODELLING METHOD USING
}

\author{
Inna Yakupova ${ }^{1, *}$, Ekaterina Chernyakova ${ }^{1}$, Anton Koksharov ${ }^{2}$ \\ ${ }^{1}$ Tomsk Polytechnic University, Lenin av. 30, Tomsk, 634050, Russia \\ ${ }^{2}$ Ltd "Kinef"
}

\begin{abstract}
In this paper the effect of pressure on the product yield and quality in industrial catalytic reforming unit was done with mathematical modelling method using. It was proved that the work at reduced pressure will increase the product yield by $2 \%$ mass, and also will enhance the yield of hydrogen and aromatic hydrocarbons.
\end{abstract}

\section{Introduction}

Catalytic naphtha reforming is one of the important and the most effective processes in the petroleum refining and petrochemical industries. Hydrogen and valuable aromatics are being produced as by-product. In most cases, this industrial process occurs in three or four adiabatic reactors mounted in series at a temperature of $480-520^{\circ} \mathrm{C}$ and an operating pressure of $0.3-2 \mathrm{MPa}$. Petroleum fraction in the range of $85-180^{\circ} \mathrm{C}$ is being used as raw material. This complex mixture consists of hydrocarbon molecules with 5-12 carbon atoms, mainly including paraffins, olefins, naphthenes, and aromatics [1-7].

Catalyst is the most important constituent of the process. Naphtha reforming catalyst is a bifunctional catalyst consists of a metal function, mainly platinum, and an acid function, usually chloride alumina. The metal function catalyzes the hydrogenation and dehydrogenation reactions and the acid function promote the isomerization and cyclization reactions. In order to achieve an optimum performance of the naphtha reforming catalyst, adequate balance between these functions is needed [1].

The yield of catalytic naphtha reforming process depends strongly on the catalyst properties. During operation, the catalyst undergoes physiochemical changes, which contribute to decrease in the activity for aromatic production.

Improving the stability and selectivity of the catalyst as well as reducing catalyst deactivation is a vital issue for enhancing the efficiency and yield of the process[1]. This practice could be achieved by mathematical modeling method application.

*Corresponding author: yakupovaiv@tpu.ru 


\section{Materials and methods}

Catalytic reforming unit L-35-11/450K with a preliminary hydro-treating is an important subject of "Komsomolsk Refinery" JSC in the Far East of Russia [8].

Foreign catalyst charge PR-9 («Criterion» company) has proven to be appropriate in operation and ensure high specified quality yield. Results of catalyst work were modeled on the mathematical model, and the results of the pressure effect on the main industrial process indicators were predicted.

In the catalytic naphtha reforming process, coke formation is the most important cause of the catalyst deactivation. It's showed on the Figure1 that the existence of formation and hydrogenation of unsaturated intermediate products of compaction is possible. Therefore, under certain conditions coke formation doesn't occur, because resins and asphaltenes (previous substances of coke) can be hydrogenated to hydrocarbons or be in equilibrium with gas-phase reaction medium. Thus, controlling of feed temperature in reactor, it could be possible to provide process operation mode with the existence of equilibrium of formation and hydrogenation of coke structures $[9,10]$.

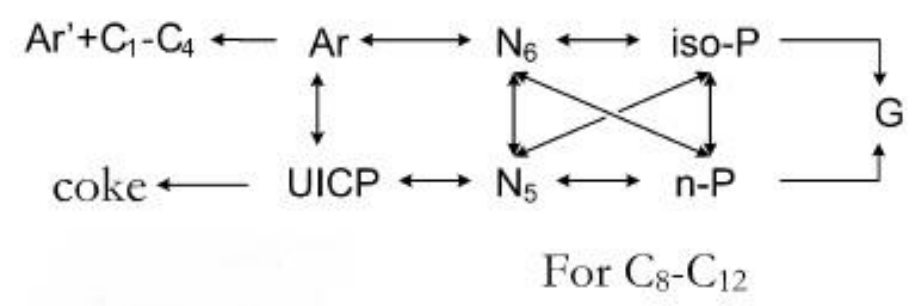

Fig.2. Formalized scheme hydrocarbon conversions C8 - C12: G - gas; n-P - normal paraffins; iso-P - izoparaffins; $\mathrm{N}_{6}$ - cyclohexanes; $\mathrm{N}_{5}$ - cyclopentanes; $\mathrm{Ar}$ - aromatic hydrocarbons; UICP - unsaturated intermediate products of compaction

But it's difficult to realize in practice, because it's required to obtain the final highoctane product, so there is an objective need for deviations from thermodynamic equilibrium. As a result, accumulation of unsaturated intermediate products of compaction occurs. However, the solution of very important industrial problem - how to find desired catalyst - is based on this contradiction [7].

The studies have been carried out using a mathematical model, which enables to consider physical and chemical laws of hydrocarbons conversion on the catalyst surface [12-14], and changes in the composition feedstock. The results of chromatographic analysis of the hydrocarbon feedstock composition, technological modes of production unit operation were used as initial data.

$$
\left\{\begin{array}{l}
G\left(\frac{\partial C_{i}}{\partial z}+\frac{\partial C_{i}}{\partial V}\right)=\sum_{j=1}^{m} W_{j} \\
G\left(\frac{\partial T}{\partial z}+\frac{\partial T}{\partial V}\right)=-\frac{1}{C_{p}^{\text {mix }}} \sum_{j=1}^{m} Q_{j} W_{i}
\end{array}\right.
$$

The initial conditions: $\mathrm{Z}=0, \mathrm{Ci}=0, \mathrm{~T}=0, \mathrm{~V}=0, \mathrm{Ci}=\mathrm{Cen}$ (at the reactor entrance), if $\mathrm{Z}=0$, $\mathrm{T}=\mathrm{Ten}$, where $\mathrm{Ci}-\mathrm{a}$ concentration of the $\mathrm{i}$-th component, $\mathrm{mol} / \mathrm{m} 3 ; \mathrm{T}-$ temperature; $\mathrm{Z}-\mathrm{a}$ raw material volume, $\mathrm{m}^{3} ; \mathrm{Wj}-\mathrm{j}$-th reaction heat, $\mathrm{mol} /\left(\mathrm{m}^{3} \cdot \mathrm{m}\right) ; \mathrm{V}-$ a volume of the catalyst layer, $\mathrm{m} 3 ; \mathrm{G}$ - a raw material flow rate, $\mathrm{m} 3 / \mathrm{h} ; \mathrm{Qj}$ - j-th reaction heat, J/mol; Cpmix - a heat capacity of mixture, $\mathrm{J} / \mathrm{mol}$. 


\section{Results}

Using the mathematical model described above results of previously catalyst charge PR-9 were analyzed (Fig. 3). Also the catalyst activity changes during 2 previous work cycles are performed.

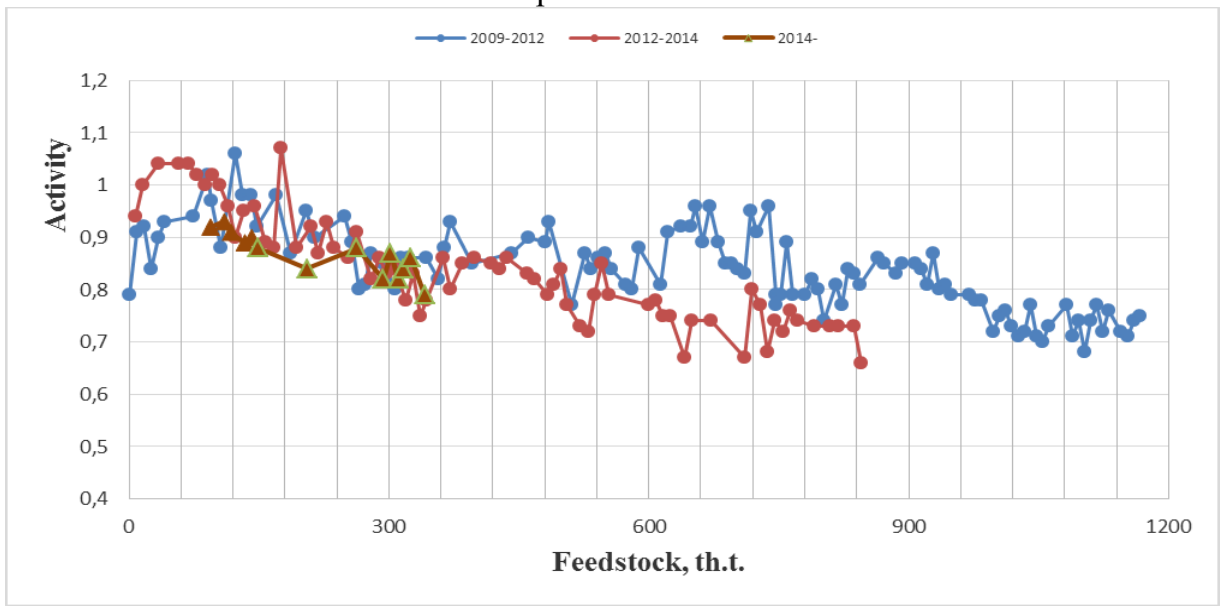

Fig.3. The comparison of catalyst current activity in different work periods

The rate of the catalyst activity change in previous cycle is slightly different on the dynamics of the current what could be compared with changes in the feedstock composition and catalyst aging.

The difference in the rate of coke accumulation (Fig.4) in the cycles is directly related to differences in technological modes of industrial plant operation.

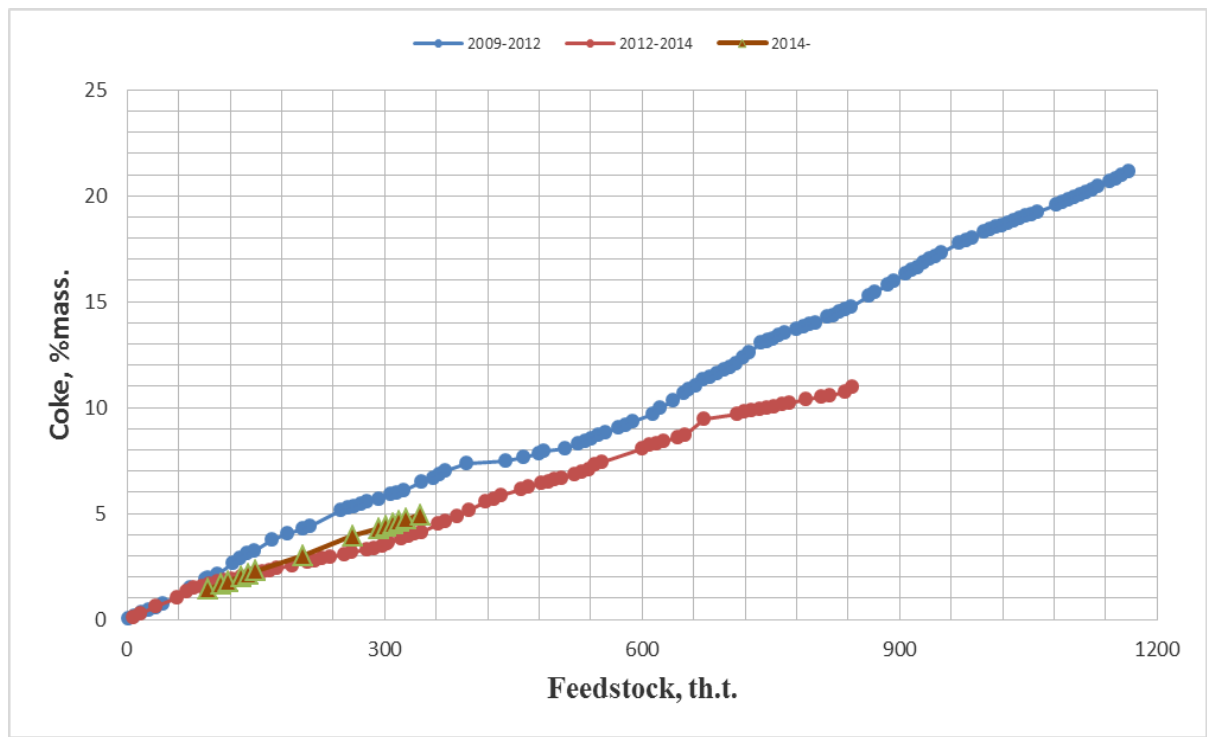

Fig.4. Coke accumulation on the catalyst in different work periods

Product output (Fig. 5) during all cycles remains quite high and ranges from 80 to $90 \%$ mass. The juddering changes product output confirm changes in the composition of the feedstock in this work period. 


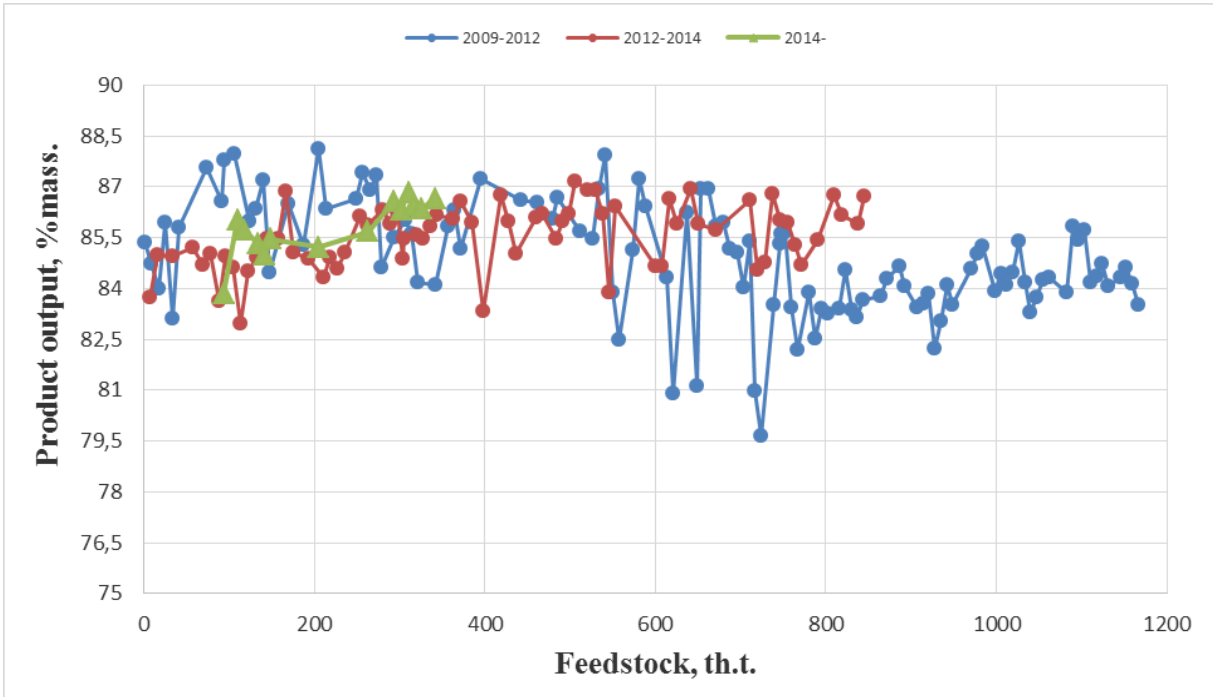

Fig.5. Product output in different work periods

The strategy of reforming technology improving goes hand in hand with a pressure reduction. However, with the pressure decreasing the coke deposition on the catalyst and the catalyst deactivation rate increase. For this reason, the reforming process with a fixed bed catalyst is not carried out at a pressure lower than 1.4 - 1.5 MPa. With a mathematical model using the pressure effect on the product yield and quality was analyzed. The results obtained are performed in Table 1.

Table 1. Pressure effect on the product yield and quality with PR-9 using

\begin{tabular}{|c|c|c|c|c|c|c|}
\hline Pressure, Mпа & $\mathbf{P}=\mathbf{1 , 7}$ & $\mathbf{P}=\mathbf{1 , 6}$ & $\mathbf{P}=\mathbf{1 , 5}$ & $\mathbf{P}=\mathbf{1 , 4}$ & $\mathbf{P}=\mathbf{1 , 3}$ & $\mathbf{P}=\mathbf{1 , 2}$ \\
\hline Octane number (research method) & 92,9 & 92,9 & 93 & 93,1 & 93,1 & 93,2 \\
\hline Aromatics, \%mass. & 60,32 & 60,27 & 60,22 & 60,22 & 60,25 & 60,18 \\
\hline Hydrogen output, \% & 1,67 & 1,63 & 1,59 & 1,55 & 1,51 & 1,47 \\
\hline Coke, \%mass. & 4,03 & 4,05 & 4,08 & 4,18 & 4,26 & 4,31 \\
\hline Product yield, \%mass. & 86,68 & 87,06 & 87,44 & 87,79 & 88,13 & 88,53 \\
\hline
\end{tabular}

The operating pressure deacreasing of the reforming process promotes its selectivity, favors the naphthenes dehydrogenation and paraffins dehydrocyclization reactions, and hydrocracking and hydrogenolysis side reactions inhibiting. Wherein pressure decreasing increases coke formation in the reactor according to the Le Chatelier's principle (Table 1).

\section{Conclusion}

With the mathematical modeling method using the calculations of PR-9 industrial characteristics have been done, as well as the effect of pressure on the quality of the product has been carried out.

From the results of studies it can be concluded that the catalyst over several cycles provides a high yield of quality product. Reduced pressure promotes the process target reaction, which leads to selectivity increasing, which in its turn promotes quality product, hydrogen and aromatics increasing. With the pressure reduction the rate of coke formation will increase, so the pressure is not recommended to drop below 1.4 MPa. 


\section{References}

1. Mohammad Reza Rahimpour, Mitra Jafari and Davood Iranshahi 2013 Applied Energy 109C 79

2. R.B. Smith 1959 Chem.Eng.Prog. 55(6) 76

3. Lapinski, M.L., Baird L., James, 2014 The McGraw Hill Companies R. 4.32004

4. D. Bommannan, R.D. Strivastava, D.N. Saraf, 1989 Chem. Eng. 67405

5. H.G. Krane, A.B. Groh, B.L. Shulman, J.H. Sinfelt World Petroleum Congress 1960

39

6. A.S. Belyi 2005 Kinetica and Catalysis 46(5) 684

7. A.V. Kravtsov, E.D. Ivanchina, S.A. Galushin, D.S. Poluboyartsev 2004 TPU

8. Inna V. Yakupova, E.S. Chernjakova (Sharova), Je.D. Ivanchina, A.S. Belyj, M.D. Smolikov 2015 Procedia Engineering 11351

9. Emilia D. Ivanchina, Ekaterina S. Sharova, Inna V. Yakupova 2014 Procedia Chemistry 10197

10. Inna V. Yakupova, Ekaterina S. Chernyakova, Emilia D. Ivanchina, Anton G. Koksharov 2015 Procedia Chemistry 15C 378

11. Zagoruiko A., Belyi A., Smolikov M., Noskov A. 2014 Catalysis today 220-222 168

12. Tataurshikov, A.; Ivanchina, E.; Krivtcova, N.; Krivtsov, E.; Syskina, A. 2015 IOP Conference Series-Earth and Environmental Science 271

13. Zagoruiko A., Belyi A., Smolikov M., Noskov A. Unstedy-state kinetic simulation of oil reforming and coke combustion processes in the fixed and moving catalyst beds 2014 Catalysis today 220168 